\title{
ANALISIS KEPUASAN PELANGGAN TERHADAP PELAYANAN JASA SURAT KILAT KHUSUS (SKH) PADA PT. POS INDONESIA (PERSERO) BATAM
}

\author{
Larisang1, M. Ansyar Bora ${ }^{2}$, Rudesty Armeliya ${ }^{3}$ \\ STT Ibnu Sina Batam \\ J1. Teuku Umar, Lubuk Baja No.55, Batam - Kepulauan Riau, 0778-425391 \\ e-mail: 1arisang@stt-ibnusina.ac.id, ansyar@stt-ibnusina.ac.id, Rudesty@stt-ibnusina.ac.id
}

\begin{abstract}
Abstrak
Salah satu tantangan terbesar PT. Pos Indonesia (Persero) Batam adalah menciptakan dan mempertahankan kepuasan pelanggan, oleh karena itu perusahaan harus memperhatikan kepuasan pelanggan agar dapat menarik dan mempertahankan pelanggan. Menurut Tjiptono (2000:146), kepuasan atau ketidakpuasan pelanggan adalah respon pelanggan terhadap evaluasi ketidaksesuaian atau diskonfirmasi yang dirasakan antara harapan sebelumnya (atau norma kinerja lainnya) dan kinerja aktual produk yang dirasakan setelah pemakaiannya.

Dari data-data yang diperoleh pada PT. Pos Indonesia (Persero) Batam di bulan September sampai bulan Desember tahun 2014, jumlah keluhan pelanggan Surat Kilat Khusus (SKH) mengalami peningkatan. Berdasarkan permasalahan tersebut perlu dilakukan pengukuran kepuasan untuk mengetahui tingkat kepuasan pelanggan terhadap pelayanan yang diberikan serta mengetahui faktorfaktor penyebab ketidakpuasan pelanggan.

Metode yang digunakan dalam penelitian ini adalah metode Importance and Performance Analysis (IPA) dan Customer Satisfaction Index (CSI). Berdasarkan hasil pengukuran yang telah dilakukan diketahui bahwa tingkat kepuasan pelanggan sebesar 0,67 (67,20\%) dimana nilai tersebut berada pada tingkat kepuasan pelanggan interval 0,66 - 0,80 (kategori puas) dan Atribut yang tingkat pelaksanaannya masih belum memuaskan pelanggan yaitu petugas memberikan perhatian penuh kepada pelanggan.
\end{abstract}

Kata kunci: Kepuasan Pelanggan, IPA dan CSI

\section{Pendahuluan}

\subsection{Latar Belakang}

Dalam era globalisasi ini persaingan bisnis jasa semakin ketat, baik di pasar nasional maupun di pasar internasional. Menurut Rangkuti (2004:90), jasa merupakan pemberian suatu kinerja atau tindakan tak kasat mata dari satu pihak kepada pihak lain. Pada umumnya jasa diproduksi dan dikonsumsi secara bersamaan, dimana interaksi antara pemberi jasa dan penerima jasa mempengaruhi hasil jasa tersebut.

Untuk mempertahankan pelanggan diperlukan pelayanan yang memuaskan, jika kinerja yang diberikan oleh perusahaan sesuai dengan harapan pelanggan, maka pelangan akan merasa puas. Semakin banyak pelanggan yang merasa puas, semakin banyak pula keuntungan yang didapatkan oleh perusahaan.

PT. Pos Indonesia (Persero) Batam adalah perusahaan yang bergerak di bidang pelayanan jasa. Perusahaan ini memberikan beberapa pelayanan jasa, salah satunya adalah pelayanan jasa Surat Kilat Khusus (SKH). PT. Pos Indonesia (Persero) Batam dituntut untuk mempertahankan kepuasan pelanggan, oleh karena itu perusahaan harus memperhatikan kepuasan pelanggan agar dapat menarik dan mempertahankan pelanggan.

Namun pada kenyataannya saat ini, masih banyak perusahaan yang hanya mencari keuntungan semata dengan mengabaikan pelayanan yang baik terhadap pelanggan dan mengabaikan kebutuhan pelanggan, sehingga membuat jasa yang dihasilkan oleh perusahaan menjadi rendah dan tidak memuaskan konsumen sehingga konsumen pun akan memberikan penilaian yang buruk terhadap perusahaan tersebut. Dari data-data yang peneliti kumpulkan pada penelitian terdahulu di PT. Pos Indonesia (Persero) Batam, terdapat keluhan pelanggan pada pelayanan jasa Surat Kilat Khusus (SKH). Jumlah keluhan ini terjadi pada bulan September sampai bulan Desember tahun 2014, dimana pada bulan September terdapat sebanyak 43 keluhan, bulan Oktober sebanyak 45 keluhan, bulan 
November sebanyak 36 keluhan dan bulan Desember sebanyak 57 keluhan. Walaupun pada bulan November mengalami penurunan dari jumlah keluhan pada bulan sebelumnya, tetapi empat bulan terakhir itu jumlah keluhan lebih banyak dari pada jumlah keluhan pada bulan-bulan sebelumnya. Berdasarkan Jumlah keluhan tersebut perlu dilakukan penelitian apakah keluhan tersebut sudah mewakili tingkat kepuasan seluruh pelanggan PT. Pos Indonesia (Persero).

\subsection{Rumusan Masalah}

Berdasarkan latar belakang masalah yang telah diuraikan di atas, maka perumusan masalah dalam penelitian ini yaitu:

1. Bagaimana tingkat kepuasan pelanggan terhadap pelayanan jasa Surat Kilat Khusus (SKH) di PT. Pos Indonesia (Persero) Batam?

2. Atribut pelayanan apa yang tingkat pelaksanaannya masih belum memuaskan pelanggan?

\subsection{Tujuan Penelitian}

Tujuan dari penelitian yang akan dilakukan adalah:

1. Mengetahui tingkat kepuasan pelanggan terhadap pelayanan jasa Surat Kilat Khusus (SKH) di PT. Pos Indonesia (Persero) Batam.

2. Mengetahui faktor-faktor penyebab ketidakpuasan pelanggan berdasarkan kualitas pelayanan.

\section{Metode Penelitian}

\subsection{Waktu dan Tempat}

Penelitian ini dilakukan pada bulan April 2015 sampai dengan bulan Oktober 2015 di PT. Pos Indonesia (Persero), Jl. Jend. Sudirman Batam Centre, Batam.

\subsection{Populasi dan Sampel}

1. Populasi

Populasi adalah totalitas dari semua objek atau individu yang akan diteliti yang mana memiliki karakteristik tertentu, jelas dan lengkap (Mutiara Mas'um, 2014). Dimana populasi dalam penelitian ini adalah pengguna jasa SKH PT. Pos Indonesia (Persero) Batam.

2. Sampel

Teknik pengambilan sampel dalam penelitian ini adalah dengan menggunakan teknik Non Probability Sampling jenis Accidental Sampling yaitu siapa saja responden yang datang yang dianggap memenuhi kriteria untuk penelitian (Apriyani, et al, 2013). Dalam menentukan jumlah sampel yang digunakan pada penelitian ini adalah sebagai berikut:

Tingkat ketelitian (level of precision) $(d)=5 \%$

Tingkat keyakinan (confidence level) $\quad=95 \%$

Nilai $Z$ dari distribusi normal $\left(Z \frac{a}{z}\right) \quad=1,96$

Proporsi yang dianggap benar $(p) \quad=95 \%$

Proporsi yang dianggap salah $(q) \quad=5 \%$

Maka jumlah sampel yang diperlukan pada penelitian ini adalah:

$n=\frac{\left(z \frac{a}{2}\right)^{2} p q}{d^{2}}$

$n=\frac{(1,96)^{2} \cdot(0,95)(0,05)}{(0,05)^{2}}$

$n=72,99 \approx 73$

Dari perhitungan di atas, dengan tingkat keyakinan 95\% dan tingkat ketelitian 5\% serta proporsi yang benar $95 \%$ dan proporsi yang salah 5\% dapat diketahui bahwa jumlah sampel yang harus diambil adalah sebanyak 73 responden.

\subsection{Variabel Penelitian}

Penelitian ini menggunakan dua variabel, yaitu:

1. Variabel Dependen (Y)

Dalam penelitian ini yang menjadi variabel dependen adalah kinerja atau kepuasan Pelanggan yang menggunakan jasa SKH di PT. Pos Indonesia (Persero) Batam. 
2. Variabel Independen (X)

Variabel independen dalam penelitian ini adalah tingkat kepentingan yang terdiri dari: 1) Bukti fisik, 2) Keandalan, 3) Ketanggapan, 4) Jaminan dan, 5) empati.

\subsection{Teknik Pengumpulan Data}

Teknik pengumpulan data yang dilakukan untuk penelitian ini adalah metode kuesioner. Metode kuesioner digunakan untuk mendapatkan data variabel $\mathrm{X}$ dan $\mathrm{Y}$.

Kuesioner yang digunakan dalam penelitian ini merupakan kuesioner tertutup dengan alternatif jawaban pada setiap pertanyaan telah tersedia. Pengukuran kuesioner ini menggunakan skala Likert dengan lima alternatif jawaban dapat dilihat pada tabel 1 berikut ini:

Tabel 1 Kriteria Tingkat Kepuasan Pelanggan

\begin{tabular}{|c|c|c|}
\hline No & Interval & Kategori \\
\hline 1. & $0,00-0,34$ & Tidak puas \\
\hline 2. & $0,35-0,50$ & Kurang puas \\
\hline 3. & $0,51-0,65$ & Cukup puas \\
\hline 4. & $0,66-0,80$ & Puas \\
\hline 5. & $0,81-1,00$ & Sangat puas \\
\hline
\end{tabular}

\subsection{Teknik Pengolahan dan Analisa Data}

Adapun tahapan pengolahan dan analisa data yang dilakukan yaitu:

1. Uji Validitas (Menggunakan Program SPSS Versi 20)

2. Uji Reliabilitas (Menggunakan Program SPSS Versi 20)

3. Importance Performance Analysis (IPA)

4. Customer Satisfaction Index (CSI), dan

5. Diagram tulang ikan (fishbone).

\section{Hasil dan Pembahasan}

\subsection{Uji Prasyarat Analisis}

1. Uji Validitas

Uji validitas kuesioner menggunakan pengujian validitas instrument yang menggunakan teknik Korelasi Product Moment. Nilai Korelasi Product Moment didapat dari hasil perhitungan SPSS 20 dan dibandingkan dengan $r_{\text {tabel }}(\mathrm{df}=\mathrm{N}(73)-2=71(0,2303)$. Nilai perhitungan dianggap valid apabila melebihi $r_{\text {tabel }}$ dan jika kurang dari $r_{\text {tabel }}$ maka nilai korelasi tersebut dianggap tidak valid. Hasil uji validitas tingkat kinerja/kepuasan dan tingkat kepentingan dapat dilihat pada tabel 2 dan tabel 3 sebagai berikut:

Tabel 2. Uji Validitas

Variabel Tingkat Kinerja/kepuasan

\begin{tabular}{|c|c|c|}
\hline $\begin{array}{c}\text { Nomor } \\
\text { Pertanyaan }\end{array}$ & $\begin{array}{c}\text { Corrected item- } \\
\text { total correlation }\end{array}$ & $\begin{array}{c}\text { Validasi } \\
\text { per item }\end{array}$ \\
\hline 1 & 0,310 & Valid \\
\hline 2 & 0,396 & Valid \\
\hline 3 & 0,423 & Valid \\
\hline 4 & 0,588 & Valid \\
\hline 5 & 0,499 & Valid \\
\hline 6 & 0,342 & Valid \\
\hline 7 & 0,627 & Valid \\
\hline 8 & 0,609 & Valid \\
\hline 9 & 0,406 & Valid \\
\hline 10 & 0,596 & Valid \\
\hline 11 & 0,364 & Valid \\
\hline 12 & 0,351 & Valid \\
\hline 13 & 0,682 & Valid \\
\hline 14 & 0,557 & Valid \\
\hline 15 & 0,645 & Valid \\
\hline
\end{tabular}

\begin{tabular}{|c|c|c|}
\hline $\begin{array}{c}\text { Nomor } \\
\text { Pertanyaan }\end{array}$ & $\begin{array}{c}\text { Corrected item- } \\
\text { total correlation }\end{array}$ & $\begin{array}{c}\text { Validasi } \\
\text { per item }\end{array}$ \\
\hline 1 & 0,572 & Valid \\
\hline 2 & 0,596 & Valid \\
\hline 3 & 0,502 & Valid \\
\hline 4 & 0,450 & Valid \\
\hline 5 & 0,687 & Valid \\
\hline 6 & 0,577 & Valid \\
\hline 7 & 0,411 & Valid \\
\hline 8 & 0,440 & Valid \\
\hline 9 & 0,533 & Valid \\
\hline 10 & 0,436 & Valid \\
\hline 11 & 0,304 & Valid \\
\hline 12 & 0,627 & Valid \\
\hline 13 & 0,551 & Valid \\
\hline 14 & 0,638 & Valid \\
\hline 15 & 0,637 & Valid \\
\hline
\end{tabular}

Tabel 3. Uji Validitas

ngkat Kepentingan 
Dari tabel di atas dapat diketahui bahwa semua data yang ada valid karena nilai $r_{\text {hitung }}>r_{\text {tabel. }}$

2. Uji Reliabilitas

Untuk uji reliabilitas menggunakan teknik Alpha Cronbach. Apabila nilai cronbach alfa standardized yang diperoleh setelah dilakukan perhitungan menggunakan aplikasi SPSS versi 20 lebih besar dari 0,6 maka pernyataan dinyatakan valid. Hasil uji reliabilitas tingkat kinerja/kepuasan dan tingkat kepentingan dapat dilihat pada tabel 4 dan tabel 5 sebagai berikut:

Tabel 4 Uji Reliabilitas Variabel Tingkat Kinerja/kepuasan

Reliability Statistics

\begin{tabular}{|c|c|}
\hline $\begin{array}{c}\text { Cronbach's } \\
\text { Alpha }\end{array}$ & N of Items \\
\hline, 775 & 15 \\
\hline
\end{tabular}

Tabel 5 Uji Reliabilitas Variabel Tingkat Kepentingan

Reliability Statistics

\begin{tabular}{|c|c|}
\hline $\begin{array}{c}\text { Cronbach's } \\
\text { Alpha }\end{array}$ & N of Items \\
\hline, 806 & 15 \\
\hline
\end{tabular}

Dari tabel di atas dapat diketahui bahwa semua data yang ada valid karena nilai cronbach alfa standardized $>0.6$,

\section{Importance and Performance Analysis (IPA)}

Metode analisis importance dan performance (IPA) dilakukan melalui pengukuran tingkat kesesuaian, yang merupakan perbandingan skor kinerja dari pihak perusahaan agar menghasilkan produk yang berkualitas tinggi dengan skor tingkat kepentingan pelanggan terhadap pelayanan produk atau jasa yang diberikan pihak perusahaan. Berdasarkan hasil pengukuran yang telah dilakukan diperoleh rata-rata tingkat kesesuaian sebesar 79,92\%, yang berarti bahwa tingkat pelayanan yang diberikan sudah sesui dengan harapan atau tingkat kepentingan pelanggan. Berikut ini diagram cartesius Importance and Performance Analysis (IPA).

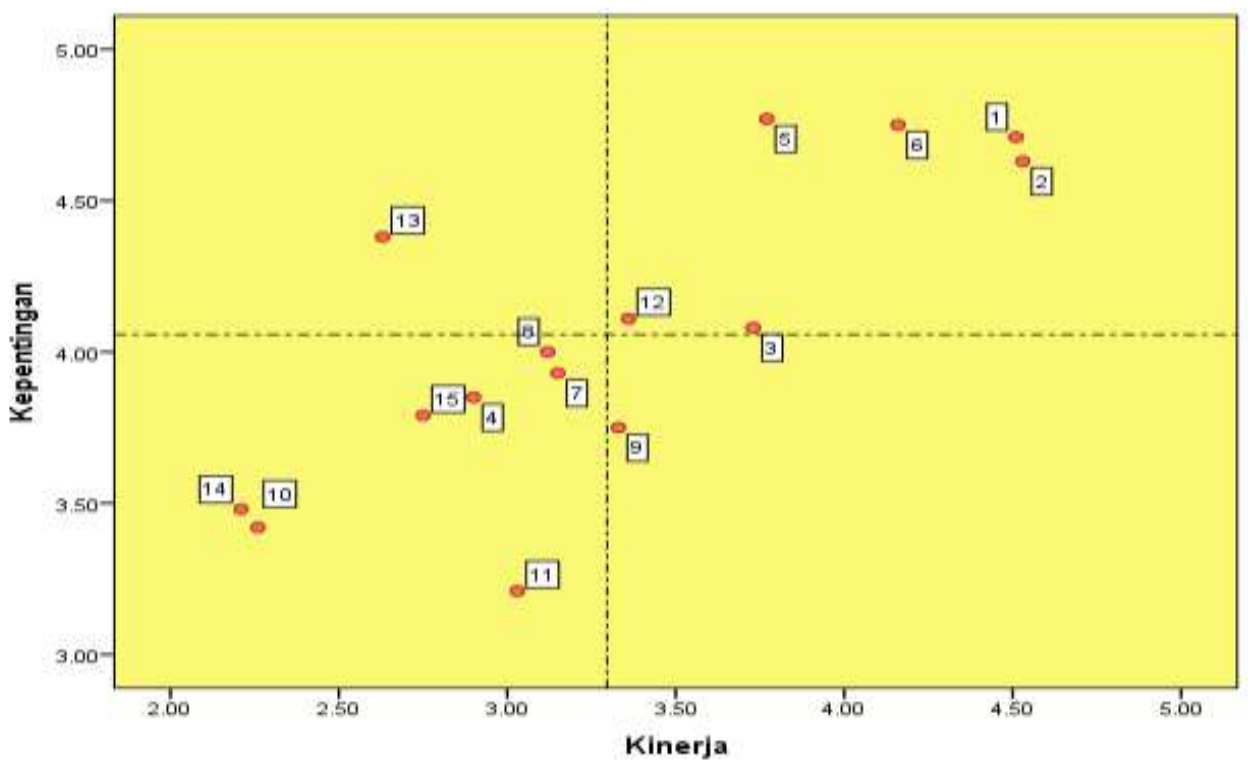

Gambar 1 Diagram Cartesius

Adapun interpretasi dari diagram kartesius tersebut dapat dijelaskan sebagai berikut:

1. Kuadran A (Prioritas Utama)

Menunjukkan atribut pelayanan yang mempengaruhi kepuasan pelanggan atau pengguna jasa Surat Kilat Khusus (SKH) pada PT. Pos Indonesia (Persero) Batam yang berada dalam kuadran ini penanganannya perlu diprioritaskan oleh perusahaan karena keberadaan atribut-atribut inilah yang dinilai sangat penting oleh pelanggan, tetapi tingkat pelaksanaannya masih belum memuaskan pelanggan. Adapun atribut pelayanan yang termasuk dalam kuadran A ini yaitu petugas memberikan perhatian penuh kepada pelanggan. 
2. Kuadran B (Pertahankan Prestasi)

Menunjukkan atribut pelayanan yang mempengaruhi kepuasan pelanggan atau pengguna jasa Surat Kilat Khusus (SKH) pada PT. Pos Indonesia (Persero) Batam yang berada dalam kuadran ini perlu dipertahankan, karena pada umumnya tingkat pelaksanaannya telah sesuai dengan kepentingan dan harapan pelanggan sehingga memuaskan pelanggan.

Atribut-atribut pelayanan yang termasuk dalam kuadran B ini yaitu:

a. Resi pengiriman SKH tertera nomor barcode

b. Resi pengiriman SKH tertera tanggal pengiriman

c. Waktu penerimaan kiriman maksimal 4 hari

d. Pelayanan yang cepat

e. Prosedur pelayanan SKH tidak berbelit-belit

f. Petugas SKH selalu sopan dalam berbicara dengan pelanggan

3. Kuadran C (Prioritas Rendah)

Menunjukkan atribut pelayanan yang mempengaruhi kepuasan pelanggan atau pengguna jasa Surat Kilat Khusus (SKH) pada PT. Pos Indonesia (Persero) Batam yang berada dalam kuadran ini dianggap kurang penting bagi pelanggan, sedangkan pelaksanaannya cukup memuaskan pelanggan.

Atribut-atribut pelayanan yang termasuk dalam kuadran C ini yaitu:

a. Konfirmasi bahwa penerima kiriman tidak di tempat

b. Petugas SKH segera melayani keluhan pelanggan

c. Petugas SKH selalu bersedia membantu pelanggan

d. Petugas SKH menjelaskan kepada pelanggan cara untuk mengetahui status pengiriman

e. Sistem online jejak lacak mudah dimengerti

f. Petugas memberikan kesempatan bertanya kepada pelanggan

g. Petugas SKH selalu memahami kebutuhan pelanggan

4. Kuadran D (Berlebihan)

Menunjukkan atribut pelayanan yang mempengaruhi kepuasan pelanggan atau pengguna jasa Surat Kilat Khusus (SKH) pada PT. Pos Indonesia (Persero) Batam yang berada dalam kuadran ini dinilai berlebihan oleh pelanggan dalam pelaksanaannya, hal ini terutama disebabkan karena pelanggan menganggap tidak terlalu penting terhadap adanya atribut tersebut, akan tetapi pelaksanaannya dilakukan dengan baik sekali oleh PT. Pos Indonesia (Persero) Batam sehingga sangat memuaskan. Adapun atribut pelayanan yang termasuk di dalam kuadran D ini yaitu petugas SKH menjawab pertanyaan-pertanyaan dari pelanggan.

\section{Customer Satisfaction Index (CSI)}

Untuk mengetahui tingkat kepuasan pelanggan terhadap pelayanan jasa Surat Kilat Khusus (SKH) pada PT. Pos Indonesia (Persero) Batam perlu dilakukan perhitungan indeks kepuasan pelanggan. Berdasarkan hasil perhitungan Customer Satisfaction Index (CSI) diperoleh nilai indeks kepuasan pelanggan sebesar 0,67, hal ini mencerminkan bahwa 49 responden merasa puas dari 73 responden $(67,20 \%$ x 73 pelanggan / 100\%) terhadap pelayanan jasa Surat Kilat Khusus (SKH) pada PT. Pos Indonesia (Persero) Batam karena nilai tersebut berada pada interval 0,66 - 0,80 (kategori puas).

\section{Simpulan dan Saran}

\subsection{Simpulan}

Berdasarkan hasil penelitian dapat disimpulkan bahwa:

1. Tingkat kepuasan pelanggan terhadap pelayanan jasa Surat Kilat Khusus (SKH) di PT. Pos Indonesia (Persero) Batam adalah sebesar 0,67 dimana nilai tersebut berada pada tingkat kepuasan pelanggan interval 0,66 - 0,80 (kategori puas).

2. Atribut yang tingkat pelaksanaannya masih belum memuaskan pelanggan yaitu petugas memberikan perhatian penuh kepada pelanggan.

\subsection{Saran}

Berdasakan kesimpulan diatas, peneliti memberikan saran sebagai berikut:

1. Perusahaan diharapkan kedepannya dapat meningkatkan pelayanan khusunya pada jasa surat khusus (SKH). 
2. Dihararapkan penelitian selanjutnya dapat menambah variabel kepuasan yang mungkin belum masuk dalam penelitian ini.

\section{Daftar Pustaka}

[1] C. Trihendradi. Step by Step SPSS 20 Analisis Data Statistik. Edisi I. Yogyakarta: ANDI. 2012.

[2] Sugiyono. Statistik Untuk Penelitian. Cetakan ke-20. Bandung: ALFABETA. 2012.

[3] Burhan Nurgiyanto, Gunawan, Marzuki. Statistik Terapan Untuk Penelitian Ilmu-Ilmu Sosial. Cetakan ke-5. Yogyakarta: Gadjah Mada University Press.

[4] Mas'um, Mutiara. Analisa Pengaruh Kualitas Pelayanan Terhadap Kepuasan Pelanggan Pada Biro Perjalanan Wisata PT. Spesial Asia Wisata Cabang Makassar. Skripsi. Makassar, Universitas Hasanussin; 2014.

[5] M. Ansyar Bora. Desain Pengukuran Kinerja Jasa Pendidikan Dengan Metode Performance Prism Studi Kasus Pada Perguruan Tinggi STT Ibnu Sina Batam. Jurnal Iltek. April 2015; Volume 10, Nomor 19; 1336-1345.

[6] Panuntun, Midya Putra. Analisis Kepuasan Pelayanan Terhadap Kepuasan Konsumen Dengan Metode Importance Performance Analysis (IPA) dan Ponential Gain In Customer Value Pada Van Oosten Coffee House Malang. Skripsi. Malang. Universitas Brawijaya Malang. 2014. 